\title{
Review Article \\ Endocannabinoid System and Synaptic Plasticity: Implications for Emotional Responses
}

\author{
María-Paz Viveros, Eva-María Marco, Ricardo Llorente, and Meritxell López-Gallardo \\ Departamento de Fisiología (Fisiología Animal II), Facultad de Biología, Universidad Complutense, 28040 Madrid, Spain
}

Received 18 December 2006; Revised 9 March 2007; Accepted 30 April 2007

Recommended by Patrice Venault

\begin{abstract}
The endocannabinoid system has been involved in the regulation of anxiety, and proposed as an inhibitory modulator of neuronal, behavioral and adrenocortical responses to stressful stimuli. Brain regions such as the amygdala, hippocampus and cortex, which are directly involved in the regulation of emotional behavior, contain high densities of cannabinoid CB1 receptors. Mutant mice lacking CB1 receptors show anxiogenic and depressive-like behaviors as well as an altered hypothalamus pituitary adrenal axis activity, whereas enhancement of endocannabinoid signaling produces anxiolytic and antidepressant-like effects. Genetic and pharmacological approaches also support an involvement of endocannabinoids in extinction of aversive memories. Thus, the endocannabinoid system appears to play a pivotal role in the regulation of emotional states. Endocannabinoids have emerged as mediators of short- and long- term synaptic plasticity in diverse brain structures. Despite the fact that most of the studies on this field have been performed using in vitro models, endocannabinoid-mediated plasticity might be considered as a plausible candidate underlying some of the diverse physiological functions of the endogenous cannabinoid system, including developmental, affective and cognitive processes. In this paper, we will focus on the functional relevance of endocannabinoid-mediated plasticity within the framework of emotional responses. Alterations of the endocannabinoid system may constitute an important factor in the aetiology of certain neuropsychiatric disorders, and, in turn, enhancers of endocannabinoid signaling could represent a potential therapeutical tool in the treatment of both anxiety and depressive symptoms.
\end{abstract}

Copyright (c) 2007 María-Paz Viveros et al. This is an open access article distributed under the Creative Commons Attribution License, which permits unrestricted use, distribution, and reproduction in any medium, provided the original work is properly cited.

\section{INTRODUCTION}

Fear is an adaptive component of the acute stress response to potentially dangerous stimuli which threaten the integrity of the individual. However, when disproportional in intensity, chronic, irreversible, and/or not associated with any actual risk, it constitutes a maladaptive response and may be symptomatic of an anxiety-related neuropsychiatric disorder such as generalized anxiety, phobia, or post-traumatic stress disorder (PTSD), among others. A diversity of mechanisms, including GABAergic, serotonergic, and noradrenergic systems, appears to be involved in the regulation of anxious states which may contribute to an appropriate emotional response to aversive events [1]. In the recent years, an increasing interest in the endocannabinoid system has arisen as part of the complex circuitry that regulates anxiety and as a crucial mediator of emotional learning. Brain distribution of cannabinoid CB1 receptors is consistent with an involvement of this system in the regulation of emotional reactivity.
Indeed, CB1 receptors are highly expressed in brain structures such as the amygdala, hippocampus, anterior cingulate cortex, and prefrontal cortex [2-8], key regions in the regulation of emotional responses. Moreover, the cannabinoid CB1 agonist CP 55,940 increased Fos immunoreactivity in brain structures known to be involved in anxiety and fear-related responses such as the central nucleus of the amygdala, the periaqueductal gray, and the paraventricular nucleus (PVN) of the hypothalamus [9].

Depression is a mood disorder in which the prevailing emotional mood is distorted or inappropriate to the circumstances. There are important links between chronic stress and depression. Upon exposure to acute stressful stimuli, the organism initiates a series of neuroendocrine short-term responses that are beneficial in terms of adaptation. However, exposure to chronic, unavoidable situations of stress may have deleterious consequences, including endocrine, emotional, and cognitive alterations associated with neuropsychiatric disorders such as depression. In this context, 
hyperactivity of the hypothalamus-pituitary-adrenal (HPA) axis with increased glucocorticoids levels appears to be linked to major depression $[10,11]$. There is evidence for an involvement of the endocannabinoid system in the regulation of neural, behavioral, and endocrine responses to aversive stimuli $[12,13]$ and it has been suggested that stress-induced dysregulation of specific components of the endocannabinoid system might be associated with deficits in behavioral flexibility that can be manifested in stress-related disorders such as PTSD and depression [14].

Endocannabinoids have been shown to act as retrograde transmitters at the synaptic level. Though the exact role of retrograde endocannabinoid signaling in vivo is not fully clarified yet, it is likely that by this mechanism endocannabinoids play important roles in synaptic transmission and plasticity, including modulation of emotional responses. Indeed, endocannabinoids have recently emerged as one of the most thoroughly investigated, and widely accepted, classes of retrograde messengers in the brain [15]. Cannabinoid-induced neuroplasticity may underlie diverse physiological functions modulated by the endocannabinoid system, that is, pain [16] and memory [17]. Synaptic plasticity within the amygdala appears to play a crucial role in acquisition, storage, and extinction of aversive memories, basic neural processes that serve adaptive behaviors, and the endocannabinoid system has emerged as a crucial mediator of such neuroplasticity-related phenomena. Marsicano et al. $[18,19]$ proposed that endocannabinoids facilitate extinction of aversive memories through their selective inhibitory effects on local inhibitory networks in the amygdala, providing evidence for a functional role of endocannabinoid release-based synaptic plasticity. Apart from the amygdala, there are some other brain areas that have been postulated as substrates for cannabinoid-induced neural plasticity such as the hippocampus and the hypothalamus where cannabinoiddependent synaptic plasticity is involved in the regulation of the stress-response system $[17,20]$. Pharmacological modulation of the endocannabinoid system has been proposed as a novel potential therapeutical strategy for the treatment of anxiety disorders and depression [21], and therapeutic interventions directed at normalization of the HPA system [11] might potentially include modulation of endocannabinoid signaling.

\section{THE ENDOCANNABINOID SYSTEM AND CANNABINOID-RELATED COMPOUNDS}

The endocannabinoid system includes the cannabinoid receptors, the endogenous lipid ligands (endocannabinoids), and the enzymatic machinery for their synthesis and inactivation. Endocannabinoids are important neuromodulators that appear to be involved in a plethora of physiological processes such as modulation of nociception, regulation of motor activity, cognitive processes, neuroprotection, immune function and inflammatory responses, antiproliferative actions in tumoral cells, control of cardiovascular system, and neurodevelopment, among others [22-29]. No- tably, the endocannabinoid system appears to be critically involved in the maintenance of homeostasis $[28,30]$. In this review, we aim to highlight its function as a stress-recovery system.

Endocannabinoids are polyunsaturated fatty acid derivatives. The ethanolamide of arachidonic acid anandamide (AEA) and 2-arachidonoylglycerol (2-AG) are the most studied endocannabinoids and have been implicated in a wide range of physiological and pathological processes. Other molecules such as 2-arachidonyl-glyceryl ether (noladin, 2-AGE), O-arachidonoyl-ethanolamine (virhodamine), and $\mathrm{N}$-arachidonoyl-dopamine (NADA) have been discovered more recently. The anabolic and catabolic pathways for AEA and 2-AG appear to rely on very complex enzymatic cascades and are in the progress of being elucidated. In brief, the enzime $\mathrm{N}$-acylphosphatidylethanolamine-specific phospholipase D (NAPE-PLD) synthesizes AEA from Narachidonoylphosphatidylethanolamine (NArPE), whereas the diacylglycerol lipase (DAGL) generates 2-AG from diacylglycerol (DAG) substrates. Due to their lipophilic nature, endocannabinoids cannot be stored in vesicles. It is widely accepted that, unlike other mediators, the endocannabinoids are synthesized and released on demand, in response to diverse physiological and pathological stimuli, and appear to exert important actions as retrograde messengers. Endocannabinoid inactivating mechanisms include cellular reuptake and hydrolysis. AEA appears to be taken up by several cell types at least in part via a facilitated transport mechanism, known as the anandamide membrane transporter (AMT), which can also transport 2-AG intracellularly. Though this putative transporter has not been isolated or cloned yet, there are compounds that are considered as inhibitors of cellular uptake. A fatty acid amide hydrolase (FAAH) is the main AEA hydrolase, whereas a monoacylglycerol lipase (MAGL) is critical in degrading 2AG. It is important to take into consideration that the actions of endocannabinoids are considered to be spatially and temporally restricted. Therefore, the effects of exogenously applied cannabinoids, which lack such selectivity, do not necessarily mimic physiological functions of the endocannabinoid system $[26,28]$. Compounds that enhance endocannabinoid signaling by inhibiting endocannabinoid reuptake (e.g., VDM11, OMDM-1, OMDM-2, UCM707) or by degradation (e.g., the FAAH inhibitors URB597, AM374, or $\mathrm{N}$-arachidonoyl-serotonin) are widely used in preclinical studies and appear to have a potential therapeutical interest. A profound discussion of biochemical aspects of the endocannabinoid system is beyond the scope of this paper, but the reader can find comprehensive excellent reviews (e.g., $[27,28,31-35])$ as well as recent papers on specific aspects such as alternative biosynthetic pathways for endocannabinoids $[36,37]$ and endocannabinoid membrane transport [38].

Cannabinoids mainly exert their pharmacological effects by the activation of specific membrane receptors. Mammalian tissues contain at least two types of cannabinoid receptors, $\mathrm{CB} 1$ and $\mathrm{CB} 2$, which are metabotropic receptors coupled to G-proteins of the Gi/o type. CB1 receptors are 
localized mainly in the central nervous system, but are also present in a variety of peripheral tissues; they are among the most abundant and widely distributed G-protein coupled receptors in the brain. Transduction systems include inhibition of adenylyl cyclase and of certain voltage-sensitive calcium channels (predominately, those found presynaptically) and activation of inwardly-rectifying potassium channels and mitogen-activated protein (MAP) kinase [39]. Autoradiographic and immunohistochemical studies have shown that $\mathrm{CB} 1$ receptors are expressed in multiple brain areas, including the olfactory bulb, neocortex, pyriform cortex, hippocampus, amygdala, basal ganglia, thalamic and hypothalamic nuclei, cerebellar cortex and brainstem nuclei. In particular, a high density of CB1 receptors is found in cortical and limbic regions associated with emotional responses. The levels of expression vary among the various brain regions and neuronal subpopulations, and there is apparently no strict correlation between levels of expression and receptor functionality. Thus, the activity of cannabinoids at CB1 receptor depends not only on the relative receptor density but also on other factors such as receptor coupling efficiency [2, 28, 4043 . It has been widely accepted that cannabinoids regulate GABA release by activation of $\mathrm{CB} 1$ receptor type, and the highest levels of $\mathrm{CB} 1$ cannabinoid receptors are found on the terminals of cholecystokinin-positive GABAergic interneurons $[44,45]$. On the other hand, the expression of CB1 receptor in glutamatergic neurons has been vigorously debated in recent years. In fact, some authors proposed that a novel non-CB1/non-CB2 cannabinoid-sensitive receptor could be responsible for the inhibition of glutamatergic neurotransmission [46, 47]. However, it has been now well established that functional cannabinoid CB1 receptors are present on glutamatergic terminals of the hippocampal formation, colocalizing with vesicular glutamate transporter 1 [48], as well as in other cortical areas (see, e.g., $[26,49,50]$ ). These evidences do not exclude that a non-CB1 receptor might exist in the brain, but there is to date no molecular evidence for such novel receptor.

Cannabinoid CB2 receptors are mostly peripherally located on immunological tissues, and therefore implicated in immunological functions. However, they have also been found within the central nervous system on neurons and glial cells with their expression mainly related to conditions of inflammation [51-53]. More recent immunohistochemical analyses have revealed immunostaining for CB2 receptors in apparent neuronal and glial processes in diverse rat brain areas, including cerebellum and hippocampus $[54,55]$. These results change the classical view of peripherally located CB2 receptors and suggest broader functional roles for these receptors.

It has been shown that some of the effects of anandamide are mediated by the transient receptor potential vanilloid type-1 channel (TRPV1), formerly called vanilloid receptor VR1 [39]. These receptors have been traditionally known for their function in sensory nerves where they mediate perception of inflammatory and thermal pain, but they are also expressed within the brain contributing to other important physiological functions. Co-expression of cannabinoid CB1 and TRPV1 receptors was found by using immunofluorescence techniques in diverse brain areas involved in the regulation of emotional responses. In particular, within the hippocampus, CB1/TRPV1 was detected on cell bodies of many pyramidal neurons throughout the CA1-CA3 subfields and in the molecular layer of dentate gyrus [56]. Interestingly, TRPV1 knockout mice (TRPV1$\mathrm{KO})$ showed less anxiety-related behavior in the light-dark test and in the elevated plus-maze than their wild-type littermates as well as less freezing to a tone after auditory fear conditioning and stress sensitization. TRPV1-KO also showed impaired hippocampus-dependent contextual fear together with a decrease in long-term potentiation (LTP) in the Schaffer collateral-commissural pathway to CA1 hippocampal neurons. These data provide first evidence for fearpromoting effects of TRPV1 with respect to both innate and conditioned fear and for a decisive role of this receptor in synaptic plasticity [57]. Collectively, these findings open new avenues for the study of possible functional relationships between $\mathrm{CB} 1$ and TRPV1 receptors, in particular regarding stress, fear, and anxiety responses.

Recently, an additional G-protein-coupled receptor (GPCR) GPR55 has been proposed as a possible new cannabinoid receptor that might play a physiological role in lipid or vascular biology [58].

\section{BASIC PRINCIPLES OF ENDOCANNABINOID- MEDIATED SYNAPTIC PLASTICITY}

One of the most salient features of the nervous system is its plasticity, including structural and functional changes in individual neurons and synapses. This characteristic is present both during brain development and in the adult life. Synaptic plasticity allows changes in the strength and number of synaptic connections between neurons. It is considered as one of the major mechanisms underlying learning and memory and appears to mediate several other functions in the central nervous system. The resulting changes in synaptic efficacy are thought to be crucial in experience-dependent modifications of neural function. A closely related concept is behavioral flexibility that allows an organism to adapt to variable environmental demands and produce adaptive responses.

Given the prominent presynaptic localization of cannabinoid $\mathrm{CB} 1$ receptors, together with its mainly inhibitory actions, cannabinoids have been proposed as local retrograde modulators, with an important role in modulating essential physiological functions and contributing in diverse synaptic plasticity phenomena [59-62]. The endocannabinoid system seems to affect neuronal excitability participating in the maintenance of homeostatic conditions in the brain $[26,63,64]$. In this respect, data obtained from conditional CB1 mutant mice suggest that the endocannabinoid system may protect neurons against excessive activity, and consequently against excitotoxicity. Marsicano et al. generated conditional mutant mice that lacked expression of the CB1 receptor in principal forebrain neurons but 
not in adjacent inhibitory interneurons. In mutant mice, the excitotoxin kainic acid (KA) induced excessive seizures in vivo, and the threshold to KA-induced neuronal excitation in vitro was severely reduced in their hippocampal pyramidal neurons. Moreover, KA administration rapidly raised hippocampal levels of anandamide and induced protective mechanisms in wild-type principal hippocampal neurons, whereas these protective mechanisms could not be triggered in mutant mice. These findings indicate that neural excitability is increased in CB1-deficient mice and that the endocannabinoid system may act as a neuroprotective system against abnormally increased discharge activity $[26,65]$. The CB1 receptor-mediated neuroprotective effect in the kainate model is apparently mediated by decrease of excitability of glutamatergic hippocampal neurons [48].

Activation of postsynaptic receptors, at diverse neuronal types, induces the release of endogenous cannabinoid compounds that move backwards across the synapse, until reaching the cannabinoid CB1 receptor, to which they bind, therefore inhibiting further neurotransmitter release. Endocannabinoid-mediated synaptic plasticity can be transient or long lasting and can be found at both excitatory and inhibitory synapses in diverse brain structures. Endocannabinoidmediated short-term synaptic plasticity includes two electrophysiological phenomena, depolarization-induced suppression of inhibition (DSI), and depolarization-induced suppression of excitation (DSE). DSI is due to a presynaptic action that reduces GABA release, while DSE results from presynaptic inhibition of glutamatergic release. There is also an involvement of the endocannabinoid system in long-term forms of synaptic plasticity. Long-term potentiation (LTP) is a long-lasting increase in the strength of a synapse, while long-term depression (LTD) is a long lasting weakening of synaptic strength. Both are mechanisms of synaptic plasticity that can persist for hours to weeks and have important implications on various forms of learning and memory. Endocannabinoid-induced long-lasting inhibition of neurotransmitter release has been found in diverse brain structures and at both excitatory and inhibitory synapses (for exhaustive discussion of these phenomena, see $[15,26,64,66$, 67]).

\section{EFFECTS OF CANNABINOIDS ON ANXIETY-RELATED RESPONSES}

The main feature of the recreational use of cannabis is that it produces a euphoriant effect. This "high" can be accompanied by decreased anxiety and increased sociability. However, cannabis can also produce dysphoric reactions, feelings of anxiety, panic, paranoia, and psychosis [68-72]. It is possible that the reasons for this lie on the bidirectional effects of cannabinoids on anxiety, with low doses having anxiolytic, and high doses having anxiogenic-like effects. The previous history of the individual and the environmental context may also critically influence the induced cannabinoid effects. Data from animal models provide further evidence for the complexity of the scenario. Low doses of sev- eral cannabinoid receptor agonists, nabilone [73], CP 55,940 $[74,75]$, and $\Delta^{9}$-tetrahydrocannabinol (THC) [76] induced anxiolytic-like effects in both the elevated plus-maze and the light-dark box. In contrast, high doses of the cannabinoid agonist HU-210 produced anxiogenic-like responses in the defensive withdrawal test [77] and enhanced emotional responding to tactile stimulation [78], and mid-high doses of CP 55,940 showed anxiogenic-like effects in the plus-maze $[74,75,79,80]$ and in the social interaction test [81].

It has been shown that exposure to chronic stress enhances the anxiety-like responsiveness to cannabinoids in rats [82], a phenomenon that is also observed in humans. Accordingly, Patel et al. [83] have recently analyzed the interactions between cannabinoids and environmental stress in the regulation of amygdalar activation in mice. The combination of restraint stress and CB1 agonist administration produced robust Fos induction within the central amygdala, indicating a synergistic interaction between environmental stress and $\mathrm{CB} 1$ receptor activation. These data suggest that the central amygdala could be an important neural substrate relevant to the context-dependent effects of cannabinoids on emotional/affective responses.

It is worth noting that, in addition to anxiety, there are other behavioral responses, such as motor activity and exploration $[75,80,81,84,85]$, that are affected by cannabinoid agonists in a biphasic manner. In general, low doses are stimulatory, whereas high doses are inhibitory. Bimodal effects of cannabinoids might be explained by two distinct populations of presynaptic CB1 receptors, with different sensitivities to cannabinoids, particularly WIN 55,212-2 (WIN), located possibly on glutamatergic and GABAergic neurons $[26,86]$. The administration of WIN resulted in a biphasic, dose-dependent effect on hippocampal acetylcholine (ACh) release: a low dose and a high dose of the compound induced a transient stimulation and a prolonged inhibition of hippocampal ACh efflux, respectively. These amphidromic responses appeared to involve the same structural entities, Gicoupled CB1 receptors, but different neuroanatomical sites. The low-dose excitatory effects were mediated in the septum, whereas the high-dose inhibitory effects were mediated locally in hippocampus. Moreover, the stimulatory and the inhibitory effects of the cannabinoid agonist involved activation of dopamine $\mathrm{D}_{1}$ and $\mathrm{D}_{2}$ receptors, respectively [7]. Local infusion of cannabinoid compounds in specific brain areas might be instrumental to identify neural pathways and neuroanatomically separated CB1 receptor subpopulations that may play distinct roles and mediate opposing actions of cannabinoids, notably, anxiolytic versus anxiogenic effects [87]. This possibility might further explain why elevation of endocannabinoids levels sometimes has effects that are different from those observed with exogenous cannabinoids [26]. An additional hypothesis which might account for the biphasic effects of cannabinoids is the possible differential implication of Gs and Gi proteins in the stimulatory and inhibitory effects, respectively [88]. It would be interesting to test this hypothesis in vivo, in relation to anxiety-related effects. 


\section{ROLE OF THE ENDOCANNABINOID SYSTEM IN THE REGULATION OF ANXIETY}

\subsection{CB1 receptor knockout mice}

The development of knockout (KO) mice deficient in $\mathrm{CB} 1(\mathrm{CB} 1-\mathrm{KO})$ receptors has provided an excellent tool to evaluate the physiological roles of the endocannabinoid system, and particularly its possible implication in the regulation of anxiety. The CB1-KO mice showed an increase in the aggressive response measured in the resident-intruder test and an anxiogenic-like behavior in the light-dark box, the elevated plus-maze test, and the social interaction test $[89,90]$. On the other hand, Marsicano et al. [18] did not find an anxiogenic-like response in the plus-maze in their CB1-KO mice. Discrepancies might be attributed to differences in the genetic background of mutant mice, and also to differences on baseline anxiety levels and to context-dependent stress elicited. In particular, CB1-KO mice exclusively showed an anxiogenic-like behavior under high-stress conditions: light in the plus-maze and unfamiliar environment in the social interaction test [18, 89-91]. An impaired action of anxiolytic drugs, such as bromazepam and buspirone, has been also observed in mutant mice [90]. This latter result suggests that functional integrity of cannabinoid CB1 receptors is necessary to achieve a complete efficacy of anxiolytic drugs, which may have consequences in the treatment of mood-related disorders, including those derived from cannabinoid abuse.

\subsection{Pharmacological blockade of $C B 1$ receptors}

Evidence for an endogenous anxiolytic cannabinoid tone also comes from certain effects of the CB1 receptor antagonist rimonabant (SR141716A). This drug has anxiogenic effects in adult rats submitted to the defensive withdrawal test and the elevated plus-maze $[79,92]$. The cannabinoid receptor agonist CP 55,940 reduced ultrasonic vocalization in rat pups separated from their mother, indicating an anxiolytic effect, and rimonabant not only reversed this effect, but also enhanced pup ultrasonic vocalizations when administered alone [93]. These results further support the view that there is an endogenous regulation of emotional states mediated by the cannabinoid system that might be present since early developmental stages. As for CB1-KO animals, certain results obtained in mice following rimonabant administration showed apparently contradictory results since this compound was found to be anxiolytic in the plus-maze [89]. These data may reflect species differences, but it seems likely that environmental context and baseline anxiety levels critically account for at least some of the discrepancies observed in the literature. The context dependency is indirectly supported by the "one-trial sensitization" phenomenon described by Rodgers et al. [94] in the plus-maze. In these experiments, the CB1 receptor antagonist had no behavioral effects in maze-naïve mice, but induced an anxiolytic-like effect in the second trial of the test.

With respect to recent clinical trials, rimonabant has been tested for its possible therapeutical application in obesity and metabolic disorders, and the most frequent adverse events resulting in discontinuation of the drug included depression and anxiety [95-97].

\subsection{Inhibitors of endocannabinoids inactivation}

As indicated above (Section 2), the enzyme FAAH catalyzes the hydrolysis of the endogenous cannabinoid anandamide. Pharmacological blockade of this enzyme by URB597 and URB532 produced anxiolytic-like effects in the elevated zeromaze in adult rats and in the isolation-induced ultrasonic emission test in rat pups. These effects were accompanied by augmented brain levels of anandamide and were prevented by $\mathrm{CB} 1$ receptor blockade. Moreover, the anxiolytic actions of URB597 were not accompanied by typical cannabinoid signs of intoxication in rodents such as catalepsy or hypothermia. These results indicate that anandamide participates in the modulation of emotional states and point to FAAH inhibition as an innovative approach to antianxiety therapy [98].

A model has been proposed to explain the possible mechanism by which the AEA-CB1 receptor system may participate in the control of anxious states. Endocannabinoids might be generated in the amygdala in response to the anxiety inducing stimulus, and would, therefore, regulate emotional states by influencing amygdala outputs [99]. This view is supported also by the fact that AEA content in the mouse basolateral amygdala rises when the animal is conditioned to expect a foot shock after hearing a tone [18]. Thus, the endocannabinoid system, and AEA in particular, might be activated in response to anxiogenic situations and this activation could be part of a negative feedback system that limits anxiety [99]. In line with this hypothesis, there are data suggesting a role of endocannabinoid signaling as an inhibitory modulator of behavioral and neuronal responses to aversive stimuli [13] and in the inhibition of stress-induced activation of HPA axis [12] (see next section). A recent paper by Patel and Hillard [100] further supports a crucial role for endocannabinoids in the induction of anxiolyticlike effects. The inhibitor of endocannabinoids metabolism, URB597, produced a linear dose-dependent anxiolytic effect. In turn, AM404 that is considered as an inhibitor of endocannabinoids uptake exerted an action that was more similar to that elicited by direct agonists, with low doses producing anxiolytic effects and the highest dose having no effect [98]. The different profiles of AM404 might be due to the fact that in addition to increasing the endocannabinoid-mediated tone, this compound can also activate TRV1 receptors [101] which, as indicated by the study by Marsh et al. quoted above [57], are also involved in the regulation of anxiety.

Collectively, a majority of evidence suggests the existence of an anxiolytic endocannabinoid tone. The modulatory role of the endocannabinoid system against stress is further supported by studies from Patel et al. [12, 13] indicating that endocannabinoids act as inhibitory modulators of both neuronal and behavioral activations during an acute stress and negatively modulate HPA axis activity (see Section 7). 


\section{CONDITIONED FEAR RESPONSES, AVERSIVE MEMORIES, AND FEAR EXTINCTION}

Neurobiological substrates of emotional-based learning have been extensively examined in animal models that allow the study of acquisition, expression, and retention of Pavlovian fear conditioning. In this paradigm, an initially innocuous/neutral stimulus (the to-be conditioned stimulus (CS); e.g., a light, tone, or odor) is paired with an innately aversive unconditioned stimulus (US; e.g., a footshock). Following several pairings, the subject comes to exhibit a conditioned fear response to the CS. Conditioned fear behavioral and physiological responses include changes in heart rate and blood pressure and freezing or cue-induced fear potentiated startle reflex. Excessive fear and anxiety are hallmarks of a variety of disabling neuropsychiatric disorders. Adaptive strategies leading to an appropriate interplay between fear expression and fear extinction are necessary for adequate coping with aversive encounters. In experimental studies like the ones mentioned above, fear inhibition is frequently studied through a procedure in which the previously fear conditioned subject is exposed to the fear-eliciting cue in the absence of any aversive event. This procedure results in a decline in conditioned fear. In other words, repeated presentation of the conditioned stimulus alone leads to extinction of the fearful response. There are clear clinical implications of research on fear extinction. Anxiety- related pathologies such as phobias and post-traumatic stress disorder (PTSD) seem to be disorders of fear dysregulation in which inhibition of fear is absent or insufficient in situations that are patently safe. In the last years, there is an increasing interest in revealing the neural mechanisms of fear inhibition, including the regions in which extinction-related plasticity occurs and the cellular and molecular processes that are implicated in this plasticity-related phenomenon (comprehensive reviews on these mechanisms can be found in [102-105]). In the present section, we will focus on the possible functional implication of the endocannabinoid system.

The use of CB1-KO mice and pharmacological blockade of $\mathrm{CB} 1$ receptors have yielded information regarding the involvement of the endocannabinoid system in conditioned fear responses. It has been reported that CB1-KO mice showed strongly impaired short- and long-term extinction in auditory fear-conditioning tests, with unaffected memory acquisition and consolidation. Consistent with this finding, pharmacological blockade of CB1 receptors with rimonabant led to a similar deficit in extinction in wild-type mice [18]. The authors also found that during the extinction protocol (exposure to the tone alone), the levels of endocannabinoids were raised within the basolateral amygdala, a region known to control extinction of aversive memories, both in mutant and normal mice. In subsequent studies, Azad et al. [19] showed that low-frequency stimulation of afferents in the lateral amygdala released endocannabinoids postsynaptically from neurons of the basolateral amygdala of mice, and thereby induced an LTP of inhibitory GABAergic synaptic transmission (LTDi) via a presynaptic mechanism. In turn, lowering inhibitory synaptic transmission significantly increased the amplitude of excitatory synaptic currents in principal neurons of the central nucleus, which is the main output site of the amygdala. LTDi was blocked by rimonabant, abolished in CB1-KO animals, and significantly enhanced in mice lacking FAAH, the anandamidedegrading enzyme [19]. More recently, it has been addressed whether CB1 blockade would similarly disrupt extinction in rats, using fear-potentiated startle as a measure of conditioned fear. The authors further investigated whether pharmacologic augmentation of CB1 activation would lead to enhancements in extinction. The results indicated that rimonabant dose-dependently blocked the extinction of conditioned fear in rats, as it does in mice. Moreover, administration of AM404, an inhibitor of endocannabinoid reuptake, led to a dose-dependent enhancement in extinction and this effect was blocked almost completely by rimonabant, indicating an implication of $\mathrm{CB} 1$ receptors. The animals treated with AM404 also showed decreased shock-induced reinstatement of fear, suggesting that this compound may reduce susceptibility to reinstatement of fear [106]. Lin et al. [107] have shown that bilateral infusion of CB1 receptor agonists into the amygdala after memory reactivation blocked reconsolidation of fear memory measured with fear-potentiated startle. These authors proposed that activation of CB1 receptors could facilitate extinction on one hand and block reconsolidation on the other.

Hölter et al. [108] have compared CB1-KO mice with their wild-type controls in an appetitively motivated operant conditioning task including food reward. During the extinction phase, when the positive reinforcement was omitted, control and CB1-KO mice showed a similar decline in accuracy of performance and total number of correct responses, accompanied by an increase in errors of omission [108]. A recent pharmacological study using rimonabant [109] further supports the notion that the cannabinoid CB1 receptor plays a pivotal role in extinction of aversive memories but is not essential for extinction of positively reinforced memories.

It has been claimed that fear conditioning in mice combines both associative and non-associative (sensitization) components and that extinction involves a significant habituation component [110]. In a more recent study, Kamprath et al. [111] have found that CB1-KO mice were severely impaired not only in extinction of the fear response to a tone after fear conditioning, but also in habituation of the fear response to a tone after sensitization with an inescapable footshock. Based on these findings, they have proposed that CB1 receptor might be critically involved in non-associative learning processes (habituation), which would contribute to the decrease in the fear response. A mouse model has been recently proposed that may allow exploring the role of the endocannabinoid system in the associative and non-associative components of fear has been recently proposed [112].

\section{CANNABINOIDS AND THE HYPOTHALAMUS- PITUITARY-ADRENAL AXIS}

An electrophysiological study by Di et al. [20] has revealed that glucocorticoids elicit a rapid, nongenomic suppression 
of glutamate release onto parvocellular neuroendocrine cells of the hypothalamic paraventricular nucleus (PVN) by stimulating the retrograde release of endocannabinoids that would subsequently activate presynaptic cannabinoid CB1 receptors. By this mechanism, endocannabinoids may be involved in the modulation of a number of peptidergic systems, including CRH. Patel et al. [12] have addressed a role of the endocannabinoid system in the modulation of stressinduced adrenocortical activity in vivo. These authors confirmed previous studies showing that rimonabant was able to increase serum corticosterone concentrations under basal conditions. Moreover, the $\mathrm{CB} 1$ receptor antagonist potentiated restraint stress-induced HPA axis activation, whereas pretreatment of mice with either a low dose of the CB1 receptor agonist CP 55,940, the endocannabinoid transport inhibitor AM404, or the FAAH inhibitor URB597 significantly decreased or eliminated restraint-induced corticosterone release. Acute restraint-induced corticosterone release was associated with a decrease in hypothalamic 2-AG content, whereas the attenuation of adrenocortical response observed after prolonged stress was associated with an increase in hypothalamic 2-AG content. In view of the above data, the following speculative model can be suggested: during resting (baseline) conditions, the HPA axis would be tonically inhibited by endocannabinoids via $\mathrm{CB} 1$ receptors located in the PVN of the hypothalamus. In this way, the endocannabinoid system might keep under control the stress response. Upon an acute stress exposure, that is, when the stress response is needed, a reduction of endocannabinoids signaling would allow the HPA axis to be activated (disinhibition). If the stress becomes chronic, endocannabinoid levels would increase again to restore a normal homeostasis.

With respect to the effects of exogenous cannabinoid agonists, in general the literature indicates that they exert a dose-dependent effect on adrenocortical activity with high doses increasing corticosterone responses [21, 84, 113]. As previously indicated, high doses of cannabinoids are also anxiogenic. However, we have found that, at certain doses, the effects of cannabinoids on anxiety can be dissociated from their effects on adrenocortical activity. Thus a high dose of the cannabinoid agonist CP 55,940 (75 $\mu \mathrm{g} / \mathrm{kg})$ induced both, anxiogenic-like effects in the plus-maze and stimulation of adrenocortical activity [80]. However, a dose of $50 \mu \mathrm{g} / \mathrm{kg}$ induced an anxiogenic-like effect in the same test, without increasing corticosterone concentrations [113].

As in the case of anxiety, literature regarding HPA axis activity supports the general concept that the pharmacological administration of exogenous cannabinoids may lead to a completely different action when compared with the physiological functions of the endocannabinoid system $[26,28,30]$.

\section{ENDOCANNABINOID SYSTEM AND DEPRESSION}

Several lines of evidence suggest that the endocannabinoid system may play a role in the aetiology of depression and could represent a new therapeutic target for its treatment. CB1-KO mice showed altered HPA axis function [90] and a higher sensitivity to exhibit depressive-like responses in the chronic unpredictable mild stress procedure, which suggests an increased susceptibility to develop an anhedonic state [114]. These characteristics together with their heightened anxiety $[89,90]$ and deficits in extinction of aversive memories [18] have been proposed to be analogous to certain symptoms of melancholic depression [115].

Several cannabinoid compounds have been evaluated in behavioral tests such as the forced swimming test (FST) and the tail-suspension test (TST) that are among the most widely used screening tests of antidepressant potential of novel compounds [116]. In the rat FST, administration of AM404 (endocannabinoid uptake inhibitor) and HU-210, a potent CB1 receptor agonist, induced decreases in immobility (indicative of antidepressant activity) that were blocked by pretreatment with the selective CB1 receptor antagonist AM251. The reduction in immobility induced by the cannabinoid compounds was comparable to that seen with the reference antidepressant desipramine [117]. In turn, the FAAH inhibitor URB597 exerted potent antidepressant-like actions in the mouse TST and the rat FST, and these effects were prevented or attenuated by rimonabant [118].

During the last years, there has been an active investigation on the implications of hippocampal neurogenesis in the pathophysiology and treatment of mood disorders. Preclinical and clinical studies indicate that stress (possibly through the action of elevated glucocorticoids) and depression lead to atrophy and loss of neurons in the adult hippocampus. On the other hand, chronic antidepressant treatment up-regulates hippocampal neurogenesis which could counteract the stress-induced damage $[119,120]$. An elegant study by Jiang et al. [121] revealed an important implication of hippocampal neurogenesis in the antidepressant and anxiolytic-like effects of cannabinoid agonists. They showed that both embryonic and adult rat hippocampal neural stem/progenitor cells were immunoreactive for cannabinoid CB1 receptors, indicating that cannabinoids could act on these receptors to regulate neurogenesis. A chronic (but not acute) treatment with the potent synthetic cannabinoid HU210 promoted neurogenesis in the hippocampal dentate gyrus of adult rats and exerted anxiolytic- and antidepressant-like effects. The cannabinoid-induced newborn neurons appeared to be of functional significance, since $\mathrm{X}$-irradiation of the hippocampus blocked both the neurogenic and behavioral effects of chronic HU210 treatment. These evidences strongly suggest that cannabinoid agonists might produce anxiolytic- and antidepressant-like effects by promoting hippocampal neurogenesis. In line with these findings, administration of the endocannabinoids uptake inhibitor AM404 prior to exposure to predator odor stress inhibited both the stress-induced activation of defensive burying and the suppression of cell proliferation in the hippocampus [122], indicating a role for endocannabinoids in the modulation of stress-induced changes in hippocampal cell proliferation.

The efficacy of antidepressants has been linked in part to their ability to reduce the activity of the HPA axis [123]. In view of the above data, it is tempting to speculate that the 
endocannabinoid system is somehow involved in the action of currently used antidepressant drugs. In favor of this hypothesis, it has been shown that chronic administration of the tricyclic antidepressant desipramine resulted in a significant increase in the density of the cannabinoid CB1 receptor in both hippocampus and hypothalamus as well as in a reduction in swim stress-induced corticosterone secretion and immediate early $c$-fos gene in the medial dorsal parvocellular region of the PVN of the hypothalamus. Moreover, acute treatment with the $\mathrm{CB} 1$ receptor antagonist AM251 before exposure to stress occluded the effects of desipramine on corticosterone secretion and neuronal activation [124].

\section{CONCLUDING REMARKS}

During the last few years, the increasing interest in the link between the endocannabinoid system and emotional responses has led to a number of interesting data derived from animal studies. These results may contribute to understand the complex scenario of cannabinoid effects in humans, and to clarify the mechanisms underlying associations between cannabis abuse and mental disorders. Results obtained from transgenic mice lacking CB1 receptors and by using CB1 receptors selective antagonists and inhibitors of endocannabinoids inactivation suggest the existence of an intrinsic endocannabinoid tone which contributes to the regulation of stress responses and anxiety. An adequate endocannabinoid function appears to be necessary for adaptive extinction of aversive memories. The endocannabinoid system might play a pivotal role in maintaining homeostasis, notably with regard to physiological and behavioral responses to acute and prolonged stress. Certain forms of endocannabinoiddependent synaptic plasticity have been proposed as crucial mechanisms subserving these phenomena. Throughout this review, we have focused on the endocannabinoid system as a major player in the modulation of synaptic transmission and plasticity considering solely interneural communication. However, the critical functional role of glial cells in maintaining a correct brain function and their implications in diverse neuropathological conditions are now clearly recognized. The new concept of the tripartite synapse in which the glial cell (notably astrocytes) plays an active role in the modulation of neurotransmission has recently emerged [125]. Expression of cannabinoid CB1 receptors and endocannabinoid synthesis and release have been observed in different types of glial cells $[126,127]$. This "glial endocannabinoid system" may have important physiological and pathological implications $[128,129]$ and it would be interesting to explore a possible role in the expression of synaptic plasticity in limbic and extra-limbic regions related to stress, fear, and anxiety responses.

Disregulation or malfunctioning of the endocannabinoid system might contribute to the aetiology of anxiety-related disorders and to certain symptoms of melancholic depression. In turn, the endocannabinoid system might constitute an interesting pharmacological target for the development of anti-anxiety and antidepressant therapies.
The involvement of the endocannabinoid system in the regulation of anxiety and its participation in the modulation of behavioral and physiological responses to aversive situations have other obvious implications. Cannabis abuse may be one of the causes disrupting the necessary balance for an appropriate function of the system. There are functional interactions between the endocannabinoid system and other monoaminergic and peptidergic systems also involved in the regulation of emotional responses $[113,130]$. Thus, the disruption of the endocannabinoid system as a consequence of cannabis abuse may alter these other neurochemical systems contributing to the development of emotional disorders. In addition to acute aversive emotional reactions to cannabis, the chronic use of this addictive drug may result in mental disturbances and neuropsychiatric disorders. In particular, there are data suggesting that exposure to cannabis derivatives is associated with a higher risk of schizophrenia, depression, and anxiety $[68-72,131,132]$. In this review, we have highlighted the importance of endocannabinoid-based neuroplasticity phenomena in the regulation of neuroendocrine and neurochemical systems implicated in the modulation of emotional responses and extinction of perseverative behaviors and inadaptative aversive memories. Consequently, it is likely that impairment of endocannabinoid-mediated synaptic transmission and plasticity contribute to the expression of at least some aspects of these psychiatric illnesses.

\section{ACKNOWLEDGMENTS}

Part of the authors' work has been supported by the Ministerio de Ciencia y Tecnología, Grants BFI2000-0611 and BFI2003-03101 and Ministerio de Sanidad y Consumo, Plan Nacional Sobre Drogas no. 3SI/05/08. Eva-María Marco and Ricardo Llorente are Predoctoral Fellows of the Ministerio de Educación y Cultura and Universidad Complutense, respectively.

\section{REFERENCES}

[1] M. J. Millan, "The neurobiology and control of anxious states," Progress in Neurobiology, vol. 70, no. 2, pp. 83-244, 2003.

[2] M. Herkenham, A. B. Lynn, M. D. Little, et al., "Cannabinoid receptor localization in brain," Proceedings of the National Academy of Sciences of the United States of America, vol. 87, no. 5, pp. 1932-1936, 1990.

[3] M. Herkenham, A. B. Lynn, M. R. Johnson, L. S. Melvin, B. R. de Costa, and K. C. Rice, "Characterization and localization of cannabinoid receptors in rat brain: a quantitative in vitro autoradiographic study," The Journal of Neuroscience, vol. 11, no. 2, pp. 563-583, 1991.

[4] M. Glass, M. Dragunow, and R. L. M. Faull, "Cannabinoid receptors in the human brain: a detailed anatomical and quantitative autoradiographic study in the fetal, neonatal and adult human brain," Neuroscience, vol. 77, no. 2, pp. 299-318, 1997.

[5] I. Katona, E. A. Rancz, L. Acsády, et al., "Distribution of $\mathrm{CB}_{1}$ cannabinoid receptors in the amygdala and their role in the control of GABAergic transmission," The Journal of Neuroscience, vol. 21, no. 23, pp. 9506-9518, 2001. 
[6] N. Hàjos and T. F. Freund, "Distinct cannabinoid sensitive receptors regulate hippocampal excitation and inhibition," Chemistry and Physics of Lipids, vol. 121, no. 1-2, pp. 73-82, 2002.

[7] E. T. Tzavara, M. Wade, and G. G. Nomikos, "Biphasic effects of cannabinoids on acetylcholine release in the hippocampus: site and mechanism of action," The Journal of Neuroscience, vol. 23, no. 28, pp. 9374-9384, 2003.

[8] M. Pistis, S. Perra, G. Pillolla, M. Melis, G. L. Gessa, and A. L. Muntoni, "Cannabinoids modulate neuronal firing in the rat basolateral amygdala: evidence for $\mathrm{CB}_{1}$ - and non- $\mathrm{CB}_{1}$ mediated actions," Neuropharmacology, vol. 46, no. 1, pp. 115-125, 2004.

[9] J. C. Arnold, A. N. Topple, P. E. Mallet, G. E. Hunt, and I. S. McGregor, "The distribution of cannabinoid-induced Fos expression in rat brain: differences between the Lewis and Wistar strain," Brain Research, vol. 921, no. 1-2, pp. 240-255, 2001.

[10] B. S. McEwen, "Mood disorders and allostatic load," Biological Psychiatry, vol. 54, no. 3, pp. 200-207, 2003.

[11] G. E. Tafet and R. Bernardini, "Psychoneuroendocrinological links between chronic stress and depression," Progress in Neuro-Psychopharmacology and Biological Psychiatry, vol. 27, no. 6, pp. 893-903, 2003.

[12] S. Patel, C. T. Roelke, D. J. Rademacher, W. E. Cullinan, and C. J. Hillard, "Endocannabinoid signaling negatively modulates stress-induced activation of the hypothalamic-pituitaryadrenal axis," Endocrinology, vol. 145, no. 12, pp. 5431-5438, 2004.

[13] S. Patel, C. T. Roelke, D. J. Rademacher, and C. J. Hillard, "Inhibition of restraint stress-induced neural and behavioural activation by endogenous cannabinoid signalling," European Journal of Neuroscience, vol. 21, no. 4, pp. 1057-1069, 2005.

[14] M. N. Hill, S. Patel, E. J. Carrier, et al., "Downregulation of endocannabinoid signaling in the hippocampus following chronic unpredictable stress," Neuropsychopharmacology, vol. 30, no. 3, pp. 508-515, 2005.

[15] B. E. Alger, "Retrograde signaling in the regulation of synaptic transmission: focus on endocannabinoids," Progress in Neurobiology, vol. 68, no. 4, pp. 247-286, 2002.

[16] S. C. Azad, V. Huge, P. Schöps, et al., "Endogenous cannabinoid system. Effect on neuronal plasticity and pain memory," Der Schmerz, vol. 19, no. 6, pp. 521-527, 2005.

[17] G. Riedel and S. N. Davies, "Cannabinoid function in learning, memory and plasticity," in Handbook of Experimental Pharmacology, vol. 168, pp. 445-477, Springer, Berlin, Germany, 2005.

[18] G. Marsicano, C. T. Wotjak, S. C. Azad, et al., "The endogenous cannabinoid system controls extinction of aversive memories," Nature, vol. 418, no. 6897, pp. 530-534, 2002.

[19] S. C. Azad, K. Monory, G. Marsicano, et al., "Circuitry for associative plasticity in the amygdala involves endocannabinoid signaling," The Journal of Neuroscience, vol. 24, no. 44, pp. 9953-9961, 2004.

[20] S. Di, R. Malcher-Lópes, K. C. Halmos, and J. G. Tasker, "Nongenomic glucocorticoid inhibition via endocannabinoid release in the hypothalamus: a fast feedback mechanism," The Journal of Neuroscience, vol. 23, no. 12, pp. 48504857, 2003.

[21] M.-P. Viveros and E.-M. Marco, "Cannabinoids, anxiety and depression," in Chronic and Common Diseases - II, J. N. Govil and V. K. Singh, Eds., vol. 18 of Recent Progress in Medicinal Plants, Stadium Press, Houston, Tex, USA, 2006.
[22] D. M. Lambert and C. J. Fowler, "The endocannabinoid system: drug targets, lead compounds, and potential therapeutic applications," Journal of Medicinal Chemistry, vol. 48, no. 16, pp. 5059-5087, 2005.

[23] C. T. Wotjak, "Role of endogenous cannabinoids in cognition and emotionality," Mini-Reviews in Medicinal Chemistry, vol. 5, no. 7, pp. 659-670, 2005.

[24] T. C. Kirkham and S. A. Tucci, "Endocannabinoids in appetite control and the treatment of obesity," CNS \& Neurological Disorders - Drug Targets, vol. 5, no. 3, pp. 272-292, 2006.

[25] K. Mackie, "Cannabinoid receptors as therapeutic targets," Annual Review of Pharmacology and Toxicology, vol. 46, pp. 101-122, 2006.

[26] G. Marsicano and B. Lutz, "Neuromodulatory functions of the endocannabinoid system," Journal of Endocrinological Investigation, vol. 29, no. 3 supplement, pp. 27-46, 2006.

[27] P. Pacher, S. Bátkai, and G. Kunos, "The endocannabinoid system as an emerging target of pharmacotherapy," Pharmacological Reviews, vol. 58, no. 3, pp. 389-462, 2006.

[28] U. Pagotto, G. Marsicano, D. Cota, B. Lutz, and R. Pasquali, "The emerging role of the endocannabinoid system in endocrine regulation and energy balance," Endocrine Reviews, vol. 27, no. 1, pp. 73-100, 2006.

[29] J. Fernández-Ruiz, J. Romero, G. Velasco, R. M. Tolón, J. A. Ramos, and M. Guzmán, "Cannabinoid $\mathrm{CB}_{2}$ receptor: a new target for controlling neural cell survival?" Trends in Pharmacological Sciences, vol. 28, no. 1, pp. 39-45, 2007.

[30] J. G. Tasker, "Rapid glucocorticoid actions in the hypothalamus as a mechanism of homeostatic integration," Obesity, vol. 14, no. 5, pp. 259S-265S, 2006.

[31] L. De Petrocellis, M. G. Cascio, and V. Di Marzo, "The endocannabinoid system: a general view and latest additions," British Journal of Pharmacology, vol. 141, no. 5, pp. 765-774, 2004.

[32] T. Bisogno, A. Ligresti, and V. Di Marzo, "The endocannabinoid signalling system: biochemical aspects," Pharmacology Biochemistry and Behavior, vol. 81, no. 2, pp. 224-238, 2005.

[33] A. Ligresti, M. G. Cascio, and V. Di Marzo, "Endocannabinoid metabolic pathways and enzymes," CNS \& Neurological Disorders - Drug Targets, vol. 4, no. 6, pp. 615-623, 2005.

[34] M. Bari, N. Battista, F. Fezza, V. Gasperi, and M. Maccarrone, "New insights into endocannabinoid degradation and its therapeutic potential," Mini-Reviews in Medicinal Chemistry, vol. 6, no. 3, pp. 257-268, 2006.

[35] I. Matias and V. Di Marzo, "Endocannabinoid synthesis and degradation, and their regulation in the framework of energy balance," Journal of Endocrinological Investigation, vol. 29, no. 3 supplement, pp. 15-26, 2006.

[36] J. Liu, L. Wang, J. Harvey-White, et al., "A biosynthetic pathway for anandamide," Proceedings of the National Academy of Sciences of the United States of America, vol. 103, no. 36, pp. 13345-13350, 2006.

[37] G. M. Simon and B. F. Cravatt, "Endocannabinoid biosynthesis proceeding through glycerophospho- $N$-acyl ethanolamine and a role for $\alpha / \beta$-hydrolase 4 in this pathway," Journal of Biological Chemistry, vol. 281, no. 36, pp. 2646526472, 2006.

[38] A. Hermann, M. Kaczocha, and D. G. Deutsch, "2arachidonoylglycerol (2-AG) membrane transport: history and outlook," The AAPS Journal, vol. 8, no. 2, pp. E409-E412, 2006. 
[39] A. C. Howlett, F. Barth, T. I. Bonner, et al., "International Union of Pharmacology. XXVII. Classification of cannabinoid receptors," Pharmacological Reviews, vol. 54, no. 2, pp. 161-202, 2002.

[40] P. Mailleux and J.-J. Vanderhaeghen, "Distribution of neuronal cannabinoid receptor in the adult rat brain: a comparative receptor binding radioautography and in situ hybridization histochemistry," Neuroscience, vol. 48, no. 3, pp. 655668, 1992.

[41] K. Tsou, S. Brown, M.C. Sañudo-Peña, K. Mackie, and J. M. Walker, "Immunohistochemical distribution of cannabinoid $\mathrm{CB}_{1}$ receptors in the rat central nervous system," Neuroscience, vol. 83, no. 2, pp. 393-411, 1998.

[42] K. Mackie, "Distribution of cannabinoid receptors in the central and peripheral nervous system," in Handbook of Experimental Pharmacology, R. G. Pertewee, Ed., vol. 168, pp. 299-325, Springer, Berlin, Germany, 2005.

[43] A. Straiker and K. Mackie, "Cannabinoids, electrophysiology, and retrograde messengers: challenges for the next 5 years," The AAPS Journal, vol. 8, no. 2, pp. E272-E276, 2006.

[44] I. Katona, B. Sperlágh, A. Sík, et al., "Presynaptically located $\mathrm{CB}_{1}$ cannabinoid receptors regulate GABA release from axon terminals of specific hippocampal interneurons," The Journal of Neuroscience, vol. 19, no. 11, pp. 4544-4558, 1999.

[45] K. Tsou, K. Mackie, M.C. Sañudo-Peña, and J. M. Walker, "Cannabinoid $\mathrm{CB}_{1}$ receptors are localized primarily on cholecystokinin-containing GABAergic interneurons in the rat hippocampal formation," Neuroscience, vol. 93, no. 3, pp. 969-975, 1999.

[46] N. Hájos, C. Ledent, and T. F. Freund, "Novel cannabinoidsensitive receptor mediates inhibition of glutamatergic synaptic transmission in the hippocampus," Neuroscience, vol. 106, no. 1, pp. 1-4, 2001.

[47] T. F. Freund, I. Katona, and D. Piomelli, "Role of endogenous cannabinoids in synaptic signaling," Physiological Reviews, vol. 83, no. 3, pp. 1017-1066, 2003.

[48] K. Monory, F. Massa, M. Egertová, et al., "The endocannabinoid system controls key epileptogenic circuits in the hippocampus," Neuron, vol. 51, no. 4, pp. 455-466, 2006.

[49] M. R. Domenici, S. C. Azad, G. Marsicano, et al., "Cannabinoid receptor type 1 located on presynaptic terminals of principal neurons in the forebrain controls glutamatergic synaptic transmission," The Journal of Neuroscience, vol. 26, no. 21, pp. 5794-5799, 2006.

[50] E. L. Hill, T. Gallopin, I. Férézou, et al., "Functional $\mathrm{CB}_{1}$ receptors are broadly expressed in neocortical GABAergic and glutamatergic neurons," Journal of Neurophysiology, vol. 97, no. 4, pp. 2580-2589, 2007.

[51] S. Galiegue, S. Mary, J. Marchand, et al., "Expression of central and peripheral cannabinoid receptors in human immune tissues and leukocyte subpopulations," European Journal of Biochemistry, vol. 232, no. 1, pp. 54-61, 1995.

[52] A. R. Schatz, M. Lee, R. B. Condie, J. T. Pulaski, and N. E. Kaminski, "Cannabinoid receptors $\mathrm{CB}_{1}$ and $\mathrm{CB}_{2}$ : a characterization of expression and adenylate cyclase modulation within the immune system," Toxicology and Applied Pharmacology, vol. 142, no. 2, pp. 278-287, 1997.

[53] M. Begg, P. Pacher, S. Bátkai, et al., "Evidence for novel cannabinoid receptors," Pharmacology and Therapeutics, vol. 106, no. 2, pp. 133-145, 2005.

[54] M. D. Van Sickle, M. Duncan, P. J. Kingsley, et al., "Identification and functional characterization of brainstem cannabinoid $\mathrm{CB}_{2}$ receptors," Science, vol. 310, no. 5746, pp. 329-332, 2005.
[55] E. S. Onaivi, H. Ishiguro, J.-P. Gong, et al., "Discovery of the presence and functional expression of cannabinoid $\mathrm{CB}_{2}$ receptors in brain," Annals of the New York Academy of Sciences, vol. 1074, pp. 514-536, 2006.

[56] L. Cristino, L. de Petrocellis, G. Pryce, D. Baker, V. Guglielmotti, and V. Di Marzo, "Immunohistochemical localization of cannabinoid type 1 and vanilloid transient receptor potential vanilloid type 1 receptors in the mouse brain," Neuroscience, vol. 139, no. 4, pp. 1405-1415, 2006.

[57] R. Marsch, E. Foeller, G. Rammes, et al., "Reduced anxiety, conditioned fear, and hippocampal long-term potentiation in transient receptor potential vanilloid type 1 receptordeficient mice," The Journal of Neuroscience, vol. 27, no. 4, pp. 832-839, 2007.

[58] D. Baker, G. Pryce, W. L. Davies, and C. R. Hiley, "In silico patent searching reveals a new cannabinoid receptor," Trends in Pharmacological Sciences, vol. 27, no. 1, pp. 1-4, 2006.

[59] T. Ohno-Shosaku, T. Maejima, and M. Kano, "Endogenous cannabinoids mediate retrograde signals from depolarized postsynaptic neurons to presynaptic terminals," Neuron, vol. 29, no. 3, pp. 729-738, 2001.

[60] R. I. Wilson and R. A. Nicoll, "Endogenous cannabinoids mediate retrograde signalling at hippocampal synapses," Nature, vol. 410, no. 6828, pp. 588-592, 2001.

[61] A. C. Kreitzer and W. G. Regehr, "Retrograde signaling by endocannabinoids," Current Opinion in Neurobiology, vol. 12, no. 3, pp. 324-330, 2002.

[62] D. Piomelli, "The molecular logic of endocannabinoid signalling," Nature Reviews Neuroscience, vol. 4, no. 11, pp. 873884, 2003.

[63] F. Grotenhermen, "Cannabinoids and the endocannabinoid system," Cannabinoids, vol. 1, no. 1, pp. 10-14, 2006.

[64] V. Chevaleyre, K. A. Takahashi, and P. E. Castillo, "Endocannabinoid-mediated synaptic plasticity in the CNS," Annual Review of Neuroscience, vol. 29, pp. 37-76, 2006.

[65] G. Marsicano, S. Goodenough, K. Monory, et al., " $\mathrm{CB}_{1}$ cannabinoid receptors and on-demand defense against excitotoxicity," Science, vol. 302, no. 5642, pp. 84-88, 2003.

[66] G. L. Gerdeman and D. M. Lovinger, "Emerging roles for endocannabinoids in long-term synaptic plasticity," British Journal of Pharmacology, vol. 140, no. 5, pp. 781-789, 2003.

[67] M. A. Diana and A. Marty, "Endocannabinoid-mediated short-term synaptic plasticity: depolarization-induced suppression of inhibition (DSI) and depolarization-induced suppression of excitation (DSE)," British Journal of Pharmacology, vol. 142, no. 1, pp. 9-19, 2004.

[68] W. Hall and N. Solowij, "Adverse effects of cannabis," The Lancet, vol. 352, no. 9140, pp. 1611-1616, 1998.

[69] C. H. Ashton, "Pharmacology and effects of cannabis: a brief review," The British Journal of Psychiatry, vol. 178, pp. 101106, 2001.

[70] G. C. Patton, C. Coffey, J. B. Carlin, L. Degenhardt, M. Lynskey, and W. Hall, "Cannabis use and mental health in young people: cohort study," British Medical Journal, vol. 325, no. 7374, pp. 1195-1198, 2002.

[71] M. Tournier, F. Sorbara, C. Gindre, J. D. Swendsen, and H. Verdoux, "Cannabis use and anxiety in daily life: a naturalistic investigation in a non-clinical population," Psychiatry Research, vol. 118, no. 1, pp. 1-8, 2003.

[72] P. N. Dannon, K. Lowengrub, R. Amiaz, L. Grunhaus, and M. Kotler, "Comorbid cannabis use and panic disorder: short term and long term follow-up study," Human Psychopharmacology, vol. 19, no. 2, pp. 97-101, 2004. 
[73] E. S. Onaivi, M. R. Green, and B. R. Martin, "Pharmacological characterization of cannabinoids in the elevated plus maze," Journal of Pharmacology and Experimental Therapeutics, vol. 253, no. 3, pp. 1002-1009, 1990.

[74] R. F. Genn, S. Tucci, E.-M. Marco, M.-P. Viveros, and S. E. File, "Anxiolytic and anxiogenic effects of the cannabinoid agonist CP 55,940 in animal tests of anxiety," Journal of Psychopharmacology, vol. 17, p. A27, 2003.

[75] E.-M. Marco, L. Pérez-Alvarez, E. Borcel, et al., "Involvement of 5- $\mathrm{HT}_{1 \mathrm{~A}}$ receptors in behavioural effects of the cannabinoid receptor agonist CP 55,940 in male rats," Behavioural Pharmacology, vol. 15, no. 1, pp. 21-27, 2004.

[76] F. Berrendero and R. Maldonado, "Involvement of the opioid system in the anxiolytic-like effects induced by $\Delta^{9}$ tetrahydrocannabinol," Psychopharmacology, vol. 163, no. 1, pp. 111-117, 2002.

[77] F. Rodriguez de Fonseca, P. Rubio, F. Menzaghi, et al., "Corticotropin-releasing factor (CRF) antagonist [DPhe12,Nle21,38,C $\alpha$ MeLeu37]CRF attenuates the acute actions of the highly potent cannabinoid receptor agonist HU210 on defensive-withdrawal behavior in rats," Journal of Pharmacology and Experimental Therapeutics, vol. 276, no. 1, pp. 56-64, 1996.

[78] D. Giuliani, F. Ferrari, and A. Ottani, “The cannabinoid agonist HU 210 modifies rat behavioural responses to novelty and stress," Pharmacological Research, vol. 41, no. 1, pp. 4753, 2000.

[79] C. Arévalo, R. De Miguel, and R. Hernández-Tristán, "Cannabinoid effects on anxiety-related behaviours and hypothalamic neurotransmitters," Pharmacology Biochemistry and Behavior, vol. 70, no. 1, pp. 123-131, 2001.

[80] S. Marín, E.-M. Marco, M. Biscaia, et al., "Involvement of the $\kappa$-opioid receptor in the anxiogenic-like effect of $\mathrm{CP}$ 55,940 in male rats," Pharmacology Biochemistry and Behavior, vol. 74, no. 3, pp. 649-656, 2003.

[81] R. F. Genn, S. Tucci, E.-M. Marco, M.-P. Viveros, and S. E. File, "Unconditioned and conditioned anxiogenic effects of the cannabinoid receptor agonist CP 55,940 in the social interaction test," Pharmacology Biochemistry and Behavior, vol. 77, no. 3, pp. 567-573, 2004.

[82] M. N. Hill and B. B. Gorzalka, "Enhancement of anxiety-like responsiveness to the cannabinoid $\mathrm{CB}_{1}$ receptor agonist $\mathrm{HU}$ 210 following chronic stress," European Journal of Pharmacology, vol. 499, no. 3, pp. 291-295, 2004.

[83] S. Patel, B. F. Cravatt, and C. J. Hillard, "Synergistic interactions between cannabinoids and environmental stress in the activation of the central amygdala," Neuropsychopharmacology, vol. 30, no. 3, pp. 497-507, 2005.

[84] F. Chaperon and M.-H. Thiébot, "Behavioral effects of cannabinoid agents in animals," Critical Reviews in Neurobiology, vol. 13, no. 3, pp. 243-281, 1999.

[85] I. S. McGregor, C. N. Issakidis, and G. Prior, "Aversive effects of the synthetic cannabinoid CP 55,940 in rats," Pharmacology Biochemistry and Behavior, vol. 53, no. 3, pp. 657-664, 1996.

[86] S. Maione, T. Bisogno, V. de Novellis, et al., "Elevation of endocannabinoid levels in the ventrolateral periaqueductal grey through inhibition of fatty acid amide hydrolase affects descending nociceptive pathways via both cannabinoid receptor type 1 and transient receptor potential vanilloid type-1 receptors," Journal of Pharmacology and Experimental Therapeutics, vol. 316, no. 3, pp. 969-982, 2006.

[87] F. A. Moreira, D. C. Aguiar, and F. S. Guimarães, "Anxiolyticlike effect of cannabinoids injected into the rat dorsolateral periaqueductal gray," Neuropharmacology, vol. 52, no. 3, pp. 958-965, 2007.

[88] E. Sulcova, R. Mechoulam, and E. Fride, "Biphasic effects of anandamide," Pharmacology Biochemistry and Behavior, vol. 59, no. 2, pp. 347-352, 1998.

[89] J. Haller, N. Bakos, M. Szirmay, C. Ledent, and T. F. Freund, "The effects of genetic and pharmacological blockade of the $\mathrm{CB}_{1}$ cannabinoid receptor on anxiety," European Journal of Neuroscience, vol. 16, no. 7, pp. 1395-1398, 2002.

[90] L. Urigüen, S. Pérez-Rial, C. Ledent, T. Palomo, and J. Manzanares, "Impaired action of anxiolytic drugs in mice deficient in cannabinoid $\mathrm{CB}_{1}$ receptors," Neuropharmacology, vol. 46, no. 7, pp. 966-973, 2004.

[91] J. Haller, B. Varga, C. Ledent, I. Barna, and T. F. Freund, "Context-dependent effects of $\mathrm{CB}_{1}$ cannabinoid gene disruption on anxiety-like and social behaviour in mice," European Journal of Neuroscience, vol. 19, no. 7, pp. 1906-1912, 2004.

[92] M. Navarro, E. Hernández, R. M. Muñoz, et al., "Acute administration of the $\mathrm{CB}_{1}$ cannabinoid receptor antagonist SR $141716 \mathrm{~A}$ induces anxiety-like responses in the rat," NeuroReport, vol. 8, no. 2, pp. 491-496, 1997.

[93] I. S. McGregor, F. N. Dastur, R. A. McLellan, and R. E. Brown, "Cannabinoid modulation of rat pup ultrasonic vocalizations," European Journal of Pharmacology, vol. 313, no. 1-2, pp. 43-49, 1996.

[94] R. J. Rodgers, J. Haller, J. Halasz, and E. Mikics, “'One-trial sensitization' to the anxiolytic-like effects of cannabinoid receptor antagonist SR141716A in the mouse elevated plusmaze," European Journal of Neuroscience, vol. 17, no. 6, pp. 1279-1286, 2003.

[95] J.-P. Després, A. Golay, L. Sjöström, et al., "Effects of rimonabant on metabolic risk factors in overweight patients with dyslipidemia," The New England Journal of Medicine, vol. 353, no. 20, pp. 2121-2134, 2005.

[96] L. F. Van Gaal, A. M. Rissanen, A. J. Scheen, et al., "Effects of the cannabinoid-1 receptor blocker rimonabant on weight reduction and cardiovascular risk factors in overweight patients: 1-year experience from the RIO-Europe study," The Lancet, vol. 365, no. 9468, pp. 1389-1397, 2005.

[97] F. X. Pi-Sunyer, L. J. Aronne, H. M. Heshmati, et al., "Effect of rimonabant, a cannabinoid-1 receptor blocker, on weight and cardiometabolic risk factors in overweight or obese patients. RIO-North America: a randomized controlled trial," Journal of the American Medical Association, vol. 295, no. 7, pp. 761-775, 2006.

[98] S. Kathuria, S. Gaetani, D. Fegley, et al., "Modulation of anxiety through blockade of anandamide hydrolysis," Nature Medicine, vol. 9, no. 1, pp. 76-81, 2003.

[99] S. Gaetani, V. Cuomo, and D. Piomelli, "Anandamide hydrolysis: a new target for anti-anxiety drugs?" Trends in Molecular Medicine, vol. 9, no. 11, pp. 474-478, 2003.

[100] S. Patel and C. J. Hillard, "Pharmacological evaluation of cannabinoid receptor ligands in a mouse model of anxiety: further evidence for an anxiolytic role for endogenous cannabinoid signaling," Journal of Pharmacology and Experimental Therapeutics, vol. 318, no. 1, pp. 304-311, 2006.

[101] S. M. Rawls, Z. Ding, and A. Cowan, "Role of TRPV1 and cannabinoid $\mathrm{CB}_{1}$ receptors in $\mathrm{AM}$ 404-evoked hypothermia in rats," Pharmacology Biochemistry and Behavior, vol. 83, no. 4, pp. 508-516, 2006.

[102] A. O. Hamm and A. I. Weike, "The neuropsychology of fear learning and fear regulation," International Journal of Psychophysiology, vol. 57, no. 1, pp. 5-14, 2005. 
[103] F. Sotres-Bayon, C. K. Cain, and J. E. LeDoux, "Brain mechanisms of fear extinction: historical perspectives on the contribution of prefrontal cortex," Biological Psychiatry, vol. 60, no. 4, pp. 329-336, 2006.

[104] K. M. Myers and M. Davis, "Mechanisms of fear extinction," Molecular Psychiatry, vol. 12, no. 2, pp. 120-150, 2007.

[105] M. Davis, K. M. Myers, J. P. Chhatwal, and K. J. Ressler, "Pharmacological treatments that facilitate extinction of fear: relevance to psychotherapy," NeuroRx, vol. 3, no. 1, pp. 8296, 2006.

[106] J. P. Chhatwal, M. Davis, K. A. Maguschak, and K. J. Ressler, "Enhancing cannabinoid neurotransmission augments the extinction of conditioned fear," Neuropsychopharmacology, vol. 30, no. 3, pp. 516-524, 2005.

[107] H.-C. Lin, S.-C. Mao, and P.-W. Gean, "Effects of intraamygdala infusion of $\mathrm{CB}_{1}$ receptor agonists on the reconsolidation of fear-potentiated startle," Learning and Memory, vol. 13, no. 3, pp. 316-321, 2006.

[108] S. M. Hölter, M. Kallnik, W. Wurst, G. Marsicano, B. Lutz, and C. T. Wotjak, "Cannabinoid $\mathrm{CB}_{1}$ receptor is dispensable for memory extinction in an appetitively-motivated learning task," European Journal of Pharmacology, vol. 510, no. 1-2, pp. 69-74, 2005.

[109] F. Niyuhire, S. A. Varvel, A. J. Thorpe, R. J. Stokes, J. L. Wiley, and A. H. Lichtman, "The disruptive effects of the $\mathrm{CB}_{1}$ receptor antagonist rimonabant on extinction learning in mice are task-specific," Psychopharmacology, vol. 191, no. 2, pp. 223 231, 2007.

[110] K. Kamprath and C. T. Wotjak, "Nonassociative learning processes determine expression and extinction of conditioned fear in mice," Learning and Memory, vol. 11, no. 6, pp. 770786, 2004.

[111] K. Kamprath, G. Marsicano, J. Tang, et al., "Cannabinoid $\mathrm{CB}_{1}$ receptor mediates fear extinction via habituation-like processes," The Journal of Neuroscience, vol. 26, no. 25, pp. 66776686, 2006.

[112] A. Siegmund and C. T. Wotjak, "A mouse model of posttraumatic stress disorder that distinguishes between conditioned and sensitised fear," Journal of Psychiatric Research, vol. 41, no. 10, pp. 848-860, 2007.

[113] M.-P. Viveros, E.-M. Marco, and S. E. File, "Endocannabinoid system and stress and anxiety responses," Pharmacology Biochemistry and Behavior, vol. 81, no. 2, pp. 331-342, 2005.

[114] M. Martin, C. Ledent, M. Parmentier, R. Maldonado, and O. Valverde, "Involvement of $\mathrm{CB}_{1}$ cannabinoid receptors in emotional behaviour," Psychopharmacology, vol. 159, no. 4, pp. 379-387, 2002.

[115] M. N. Hill and B. B. Gorzalka, "Is there a role for the endocannabinoid system in the etiology and treatment of melancholic depression?" Behavioural Pharmacology, vol. 16, no. 56, pp. 333-352, 2005.

[116] R. McArthur and F. Borsini, "Animal models of depression in drug discovery: a historical perspective," Pharmacology Biochemistry and Behavior, vol. 84, no. 3, pp. 436-452, 2006.

[117] M. N. Hill and B. B. Gorzalka, "Pharmacological enhancement of cannabinoid $\mathrm{CB}_{1}$ receptor activity elicits an antidepressant-like response in the rat forced swim test," $E$ uropean Neuropsychopharmacology, vol. 15, no. 6, pp. 593-599, 2005.

[118] G. Gobbi, F. R. Bambico, R. Mangieri, et al., "Antidepressantlike activity and modulation of brain monoaminergic transmission by blockade of anandamide hydrolysis," Proceedings of the National Academy of Sciences of the United States of America, vol. 102, no. 51, pp. 18620-18625, 2005.
[119] G. A. Elder, R. De Gasperi, and M. A. Gama Sosa, "Research update: neurogenesis in adult brain and neuropsychiatric disorders," Mount Sinai Journal of Medicine, vol. 73, no. 7, pp. 931-940, 2006.

[120] J. L. Warner-Schmidt and R. S. Duman, "Hippocampal neurogenesis: opposing effects of stress and antidepressant treatment," Hippocampus, vol. 16, no. 3, pp. 239-249, 2006.

[121] W. Jiang, Y. Zhang, L. Xiao, et al., "Cannabinoids promote embryonic and adult hippocampus neurogenesis and produce anxiolytic- and antidepressant-like effects," Journal of Clinical Investigation, vol. 115, no. 11, pp. 3104-3116, 2005.

[122] M. N. Hill, J. S. Kambo, J. C. Sun, B. B. Gorzalka, and L. A. M. Galea, "Endocannabinoids modulate stress-induced suppression of hippocampal cell proliferation and activation of defensive behaviours," European Journal of Neuroscience, vol. 24, no. 7, pp. 1845-1849, 2006.

[123] B. L. Mason and C. M. Pariante, "The effects of antidepressants on the hypothalamic-pituitary-adrenal axis," Drug News \& Perspectives, vol. 19, no. 10, pp. 603-608, 2006.

[124] M. N. Hill, W.-S. V. Ho, K. J. Sinopoli, V. Viau, C. J. Hillard, and B. B. Gorzalka, "Involvement of the endocannabinoid system in the ability of long-term tricyclic antidepressant treatment to suppress stress-induced activation of the hypothalamic-pituitary-adrenal axis," Neuropsychopharmacology, vol. 31, no. 12, pp. 2591-2599, 2006.

[125] G. Perea and A. Araque, "Glial calcium signaling and neuronglia communication,” Cell Calcium, vol. 38, no. 3-4, pp. 375382, 2005.

[126] N. Stella, "Cannabinoid signaling in glial cells," GLIA, vol. 48, no. 4, pp. 267-277, 2004.

[127] M. R. Pazos, E. Núñez, C. Benito, R. M. Tolón, and J. Romero, "Functional neuroanatomy of the endocannabinoid system," Pharmacology Biochemistry and Behavior, vol. 81, no. 2, pp. 239-247, 2005.

[128] C. Benito, W.-K. Kim, I. Chavarría, et al., "A glial endogenous cannabinoid system is upregulated in the brains of macaques with simian immunodeficiency virus-induced encephalitis," The Journal of Neuroscience, vol. 25, no. 10, pp. 2530-2536, 2005.

[129] I. Galve-Roperh, T. Aguado, D. Rueda, G. Velasco, and M. Guzmán, "Endocannabinoids: a new family of lipid mediators involved in the regulation of neural cell development," Current Pharmaceutical Design, vol. 12, no. 18, pp. 23192325, 2006.

[130] M. van der Stelt and V. Di Marzo, "The endocannabinoid system in the basal ganglia and in the mesolimbic reward system: implications for neurological and psychiatric disorders," European Journal of Pharmacology, vol. 480, no. 1-3, pp. 133150, 2003.

[131] M.-P. Viveros, R. Llorente, E. Moreno, and E.-M. Marco, "Behavioural and neuroendocrine effects of cannabinoids in critical developmental periods," Behavioural Pharmacology, vol. 16, no. 5-6, pp. 353-362, 2005.

[132] L. Arseneault, M. Cannon, J. Witton, and R. M. Murray, "Causal association between cannabis and psychosis: examination of the evidence," The British Journal of Psychiatry, vol. 184, pp. 110-117, 2004. 

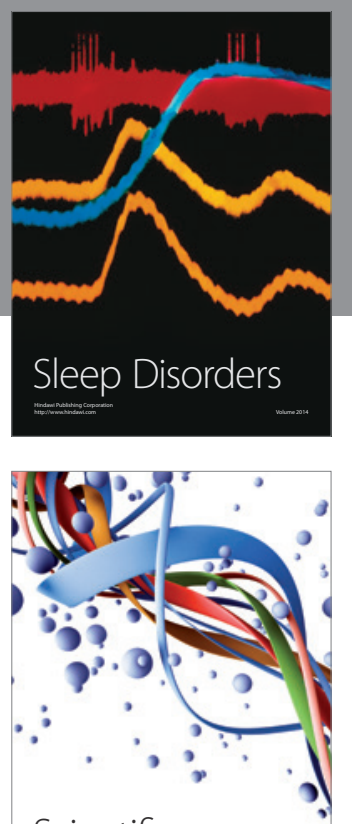

Scientifica
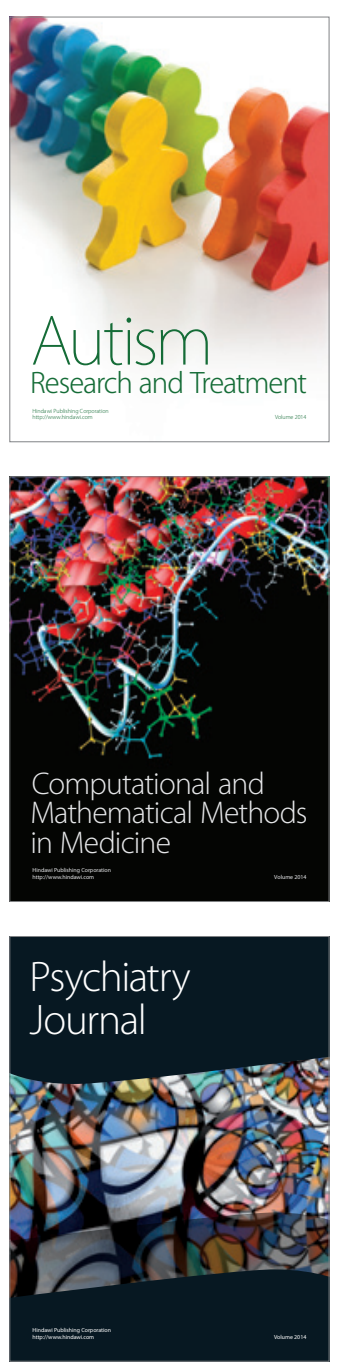
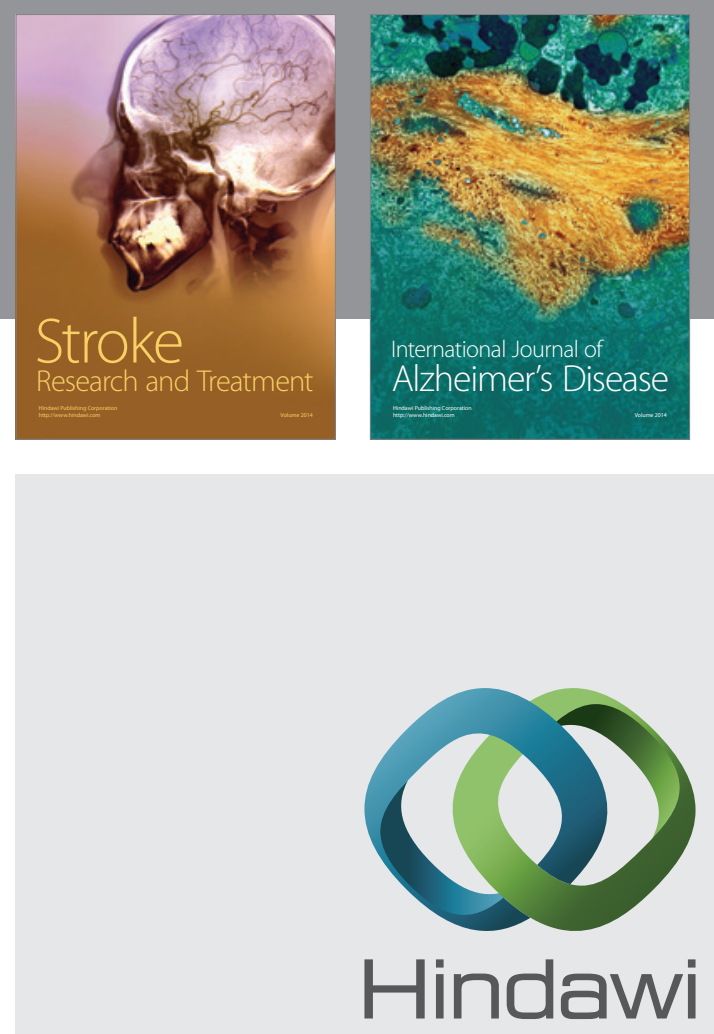

Submit your manuscripts at

http://www.hindawi.com
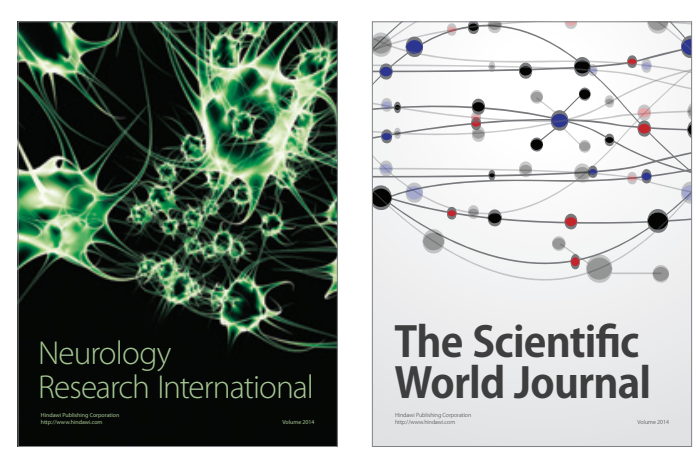

The Scientific World Journal

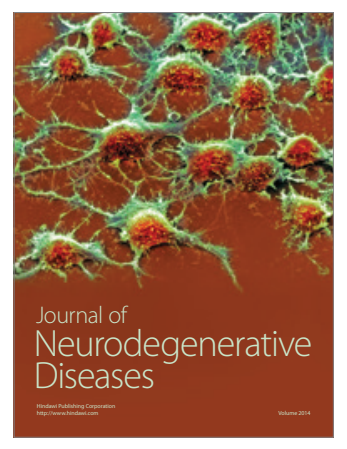

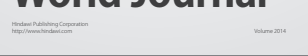

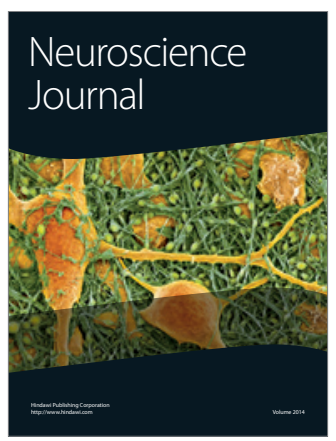

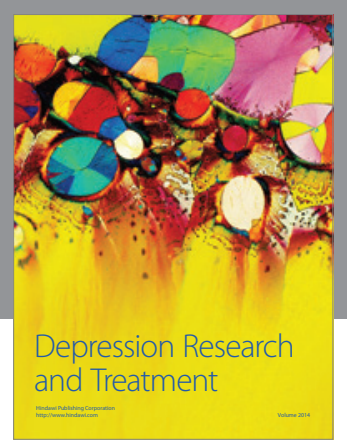
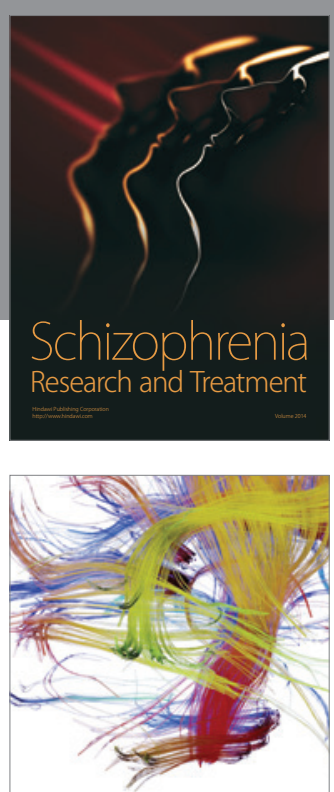

Brain Science

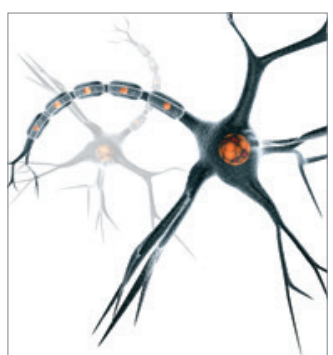

Neural Plasticity
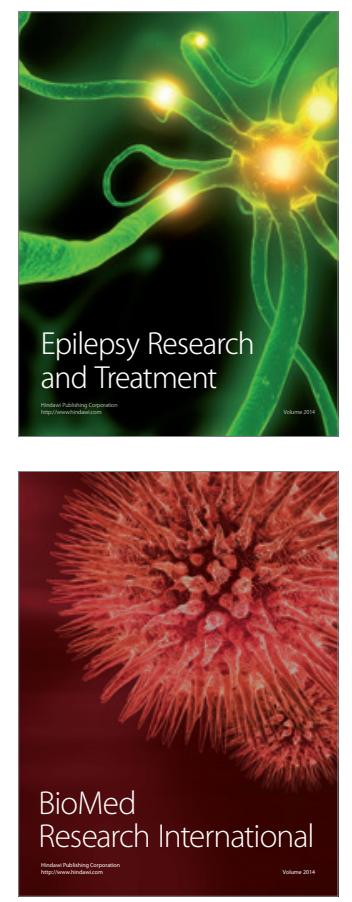

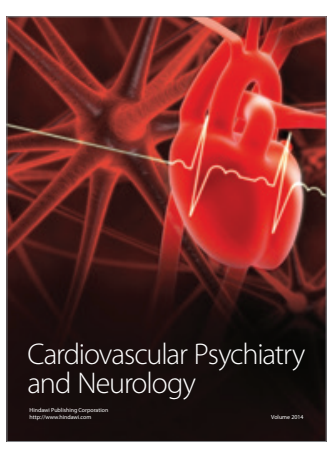

Parkinson's

Disease
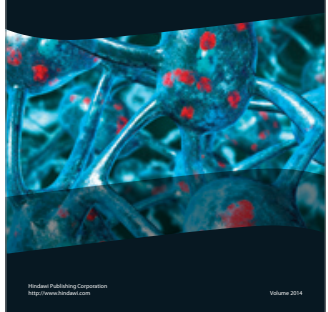